\title{
Cretopachyderes gen. nov., a new remarkable click beetle (Coleoptera: Elateridae: Agrypninae) from the mid-Cretaceous Burmese amber
}

\author{
Robin Kundrata $^{1}$, Alexander S. Prosvirov ${ }^{2}$, Roger Long ${ }^{3,4}$, and Gabriela Packova ${ }^{1}$ \\ ${ }^{1}$ Department of Zoology, Faculty of Science, Palacký University Olomouc, 17. listopadu 50, \\ 77146, Olomouc, Czech Republic \\ ${ }^{2}$ Department of Entomology, Faculty of Biology, Moscow State University, Leninskie gory 1/12, 119234, Moscow, Russia \\ ${ }^{3}$ Myanmar Amber Museum, 136 37th Street, 1143, Yangon, Myanmar \\ ${ }^{4}$ private address: 7305 Crape Myrtle Way, Sarasota, Florida 34241, USA
}

Correspondence: Robin Kundrata (robin.kundrata@upol.cz)

Received: 4 August 2021 - Revised: 25 September 2021 - Accepted: 8 October 2021 - Published: 3 November 2021

\begin{abstract}
Although the Mesozoic Era played an important role in the evolution and diversification of Elateridae, the Cretaceous click-beetle fauna remains very poorly known. Here we describe Cretopachyderes burmitinus gen. et sp. nov. based on a single specimen from the mid-Cretaceous Burmese amber. This species is remarkable for its extremely long posterior angles of pronotum, which is a unique character among fossil Elateridae. We discuss the diagnostic characters of Cretopachyderes gen. nov. and tentatively place it to subfamily Agrypninae close to extant genus Pachyderes Guérin-Méneville, 1829.
\end{abstract}

\section{Introduction}

Elateridae, commonly known as click beetles, is the speciesrich cosmopolitan family belonging to the polyphagan superfamily Elateroidea. The typical representatives have a compact body and a pro-mesothoracic clicking mechanism (Costa et al., 2010); however, this group also includes several soft-bodied lineages (Kundrata and Bocak, 2019). Despite recent progress in understanding the composition, phylogeny, and classification of Elateridae, all these aspects remain open to further study (Kundrata et al., 2018a; Bi et al., 2019; Kundrata et al., 2019b; Kusy et al., 2021; Douglas et al., 2021). The most recent study on the phylogeny of Elateridae (Douglas et al., 2021) showed that the Lampyridae and related bioluminescent families may be in fact derived click beetles, which means that the widely delimited Elateridae clade comprises more than 13500 extant species worldwide (Costa et al., 2010; Douglas et al., 2021). The fossil record of Elateridae includes 261 species classified in 99 genera and nine subfamilies (Kundrata et al., 2020, 2021). The Mesozoic click-beetle diversity includes 143 species, with most of them described from the Jurassic Karatau (Dolin, 1975, 1976, 1980); however, the family placement of many of them needs revision (Muona et al., 2020; Kundrata et al., 2021). Only three click-beetle species have been recorded from the mid-Cretaceous Burmese amber to date (Cockerell, 1917; Otto, 2019), although this deposit is rich in the Elateridae inclusions (Kundrata et al., 2021). In this study, we report a discovery of a new enigmatic Burmese-amber click-beetle genus with extremely pronounced posterior angles of pronotum, which is a character known only in several present-day Elateridae lineages.

\section{Material and methods}

The amber piece was photographed submerged in a Petri dish of cedar wood oil to help correct for the distortion caused by the curved faces of the amber. Images were taken using the following photographic equipment: Kaiser Copy Stand (stand), Cognisys StackShot Macro Rail Package (image capturing system), Canon 5D Mark II (camera), Canon MP-E $65 \mathrm{~mm}$ f/2.8 1-5× (lens), Canon Macro Twin Lite MT24EX TTL (macro main flash), and Lume Cube 2.0 LED 
fixed light (additional lighting). Adobe Photoshop Lightroom CC (version 2019-20.0.5) was used for the lens correction and basic editing, and Adobe Photoshop CC (version 201920.0.5) was used for the noise reduction and image refinement. Stacks of photographs were combined with the software Zerene Stacker Professional (version 1.04, Zerene Systems, Richland, WA, USA), applying the DMap method. Final image plates were assembled using Adobe Photoshop CC (version 2019-20.0.5).

Morphological terminology follows Costa et al. (2010) and Kundrata et al. (2019b), and the Elateridae classification follows Kundrata et al. (2019a). The holotype of the newly described species was originally deposited in the collection of the Myanmar Amber Museum, Yangon, Myanmar (MAM), which is currently closed. Therefore, the holotype is currently in the personal collection of the third author (Roger Long, Sarasota, FL, USA) and will be eventually sent back to the MAM when it opens again. The ZooBank LSID number for this publication is urn:lsid:zoobank.org:pub:1894924BA1FE-43AF-A97F-50DAE387E9C0.

\section{Systematic palaeontology}

Order Coleoptera Linnaeus, 1758

Suborder Polyphaga Emery, 1886

Series Elateriformia Crowson, 1960

Superfamily Elateroidea Leach, 1815

Family Elateridae Leach, 1815

Subfamily Agrypninae Candèze, 1857

Tribe Incertae sedis

Genus Cretopachyderes gen. nov.

urn:1sid:zoobank.org:act:6F4C5567-C295-4E9C-8713FEB5E61381EF; Figs. 1-4.

\section{Type species}

Cretopachyderes burmitinus sp. nov., here designated.

\section{Etymology}

Derived from the words "Creto" (referring to the Cretaceous Period) and "Pachyderes" (a genus name in Elateridae) (Fig. 5). Gender: masculine.

\section{Diagnosis}

Cretopachyderes gen. nov. can be readily recognized among other Mesozoic click-beetle genera by the distinctly pronounced posterior angles of pronotum (Figs. 1-3). Additionally, it can be recognized by the following combina- tion of characters: body oval-elongate, rather flattened, antenna serrate, relatively short, almost reaching posterior angles of pronotum, pronotal sublateral carina distinct, coming from subapical inner part of posterior angle and running medially across whole length of posterior angle, hypomeron with posterior margin subapically subrectangularly emarginate, pronotosternal sutures anteriorly open, prosternal process very slightly gradually narrowed toward apex, subapically abruptly narrowed, tibia shorter than femur and also shorter than tarsus, without paired spurs, tarsomeres simple (Figs. 1-4).

\section{Description}

Adult. Body (Fig. 1) oval-elongate, rather flattened. Head (Figs. 1-3) retracted to prothorax, less than half as wide as pronotum. Eyes moderately large, with their major part hidden in prothorax. Antenna (Figs. $2 \mathrm{~b} ; 3 \mathrm{c}-\mathrm{e}$ ) serrate from antennomere 4 , relatively short, almost reaching posterior angles of pronotum; antennomere 3 short, slightly longer than wide, distinctly shorter than antennomere 4 , antennomeres 4-10 elongate, with short serrations; terminal antennomere simple, elongate, apically narrowed and narrowly rounded. Terminal maxillary palpomere securiform. Pronotum (Figs. 1-3) widest at one-third (without posterior angles), otherwise widest at posterior angles when posterior angles included, distinctly wider than long if measured along midline (without posterior angles), otherwise slightly longer than wide when posterior angles included. Anterior angles very short; lateral sides rounded anteriorly, then subparallel; posterior angles very long, surpassing humeral part of elytra, sharp, oriented posteriorly, with inner margin with distinct tooth and outer margin slightly concave. Lateral carina distinct, complete. Sublateral carina distinct, coming from subapical inner part of posterior angle and running medially across whole length of posterior angle. Hypomeron with posterior margin subapically subrectangularly emarginate. Pronotosternal sutures almost straight, anteriorly open. Prosternum (Figs. 2b; 3c) elongate; prosternal lobe short, rounded; prosternal process robust, very slightly gradually narrowed toward apex, subapically abruptly narrowed. Scutellar shield (Figs. 1b; 2a; 3a; 4a) longer than wide, narrowly rounded posteriorly. Elytra (Figs. 1a, c; 2a, b; 3a, c; $4 \mathrm{a}, \mathrm{b})$ together about twice as long as wide, widest at basal third, with striae formed by lines of fine punctures; interstriae smooth, slightly convex. Metaventrite wider than long. Metacoxal plate (Fig. 2b) with basal portion wide, posteriorly widely roundly emarginate, then obliquely abruptly narrowed towards body edge. Leg (Figs. 1a-c; 2a-b; 4dh) slender, femur robust, elongate; tibia shorter than femur, densely covered with thick long sharp setae, without distinct spurs; tarsus slender, elongate, distinctly longer than tibia; tarsomeres simple; claws simple. Abdomen (Figs. 2b; 4c) with ventrites $1-4$ subequal in length; ventrite 5 longer, narrowly rounded to subacute apically. 


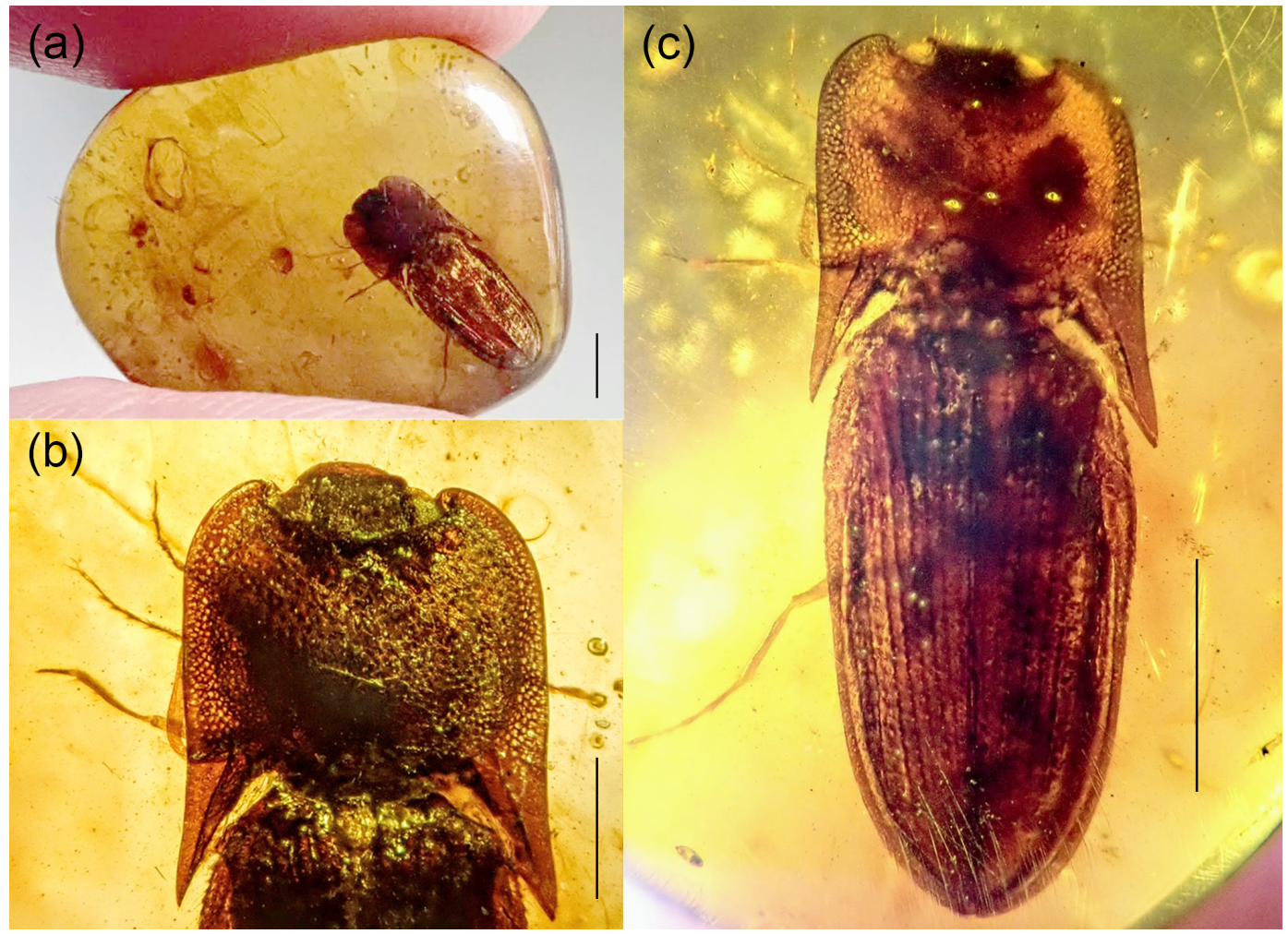

Figure 1. Cretopachyderes burmitinus gen. et sp. nov., holotype: (a) general view of the inclusion in amber stone; (b) anterior part of body, dorsal view; (c) habitus, dorsal view. Scale bar equals $2.0 \mathrm{~mm}(\mathbf{a}, \mathbf{c})$ and $1.0 \mathrm{~mm}$ (b).

\section{Composition and distribution}

Cretopachyderes gen. nov. is a monotypic genus and is known exclusively from the Cretaceous Burmese amber.

Cretopachyderes burmitinus sp. nov.

urn:lsid:zoobank.org:act:428E20BE-1DC2-482F-

B81C-A8BC1439A027; Figs. 1-4.

\section{Type material}

Holotype, adult specimen, sex unknown, MAM0012 (MAM). A complete beetle is included in a transparent, yellow amber piece with dimensions of $13.5 \times 15.9 \times 4 \mathrm{~mm}$, without any syninclusions, only with air bubbles.

\section{Type stratum and age}

Mid-Cretaceous (upper Albian to lower Cenomanian) (Shi et al., 2012; Mao et al., 2018; Yu et al., 2019).

\section{Type locality}

Hukawng Valley, Tanai Township, Myitkyina District, Kachin State, northern Myanmar.

\section{Etymology}

The specific epithet "burmitinus" is derived from "burmite" (mid-Cretaceous Burmese amber).

\section{Diagnosis}

As for the genus (vide supra).

\section{Description}

Adult. Body (Fig. 1) about $7.5 \mathrm{~mm}$ long (measured from frons to apex of elytra) and $2.6 \mathrm{~mm}$ wide (measured across widest part of pronotum), oval-elongate, rather flattened; dorsally sparsely setose.

Head (Figs. 1-3) subquadrate, retracted to prothorax, 0.45 times as wide as pronotum width. Eyes moderately large, strongly protuberant, with their major part hidden in prothorax. Labrum wider than long, anteriorly slightly concave. Antenna (Figs. 2b; 3c-e) serrate from antennomere 4, relatively short, almost reaching posterior angles of pronotum; scape robust; pedicel not well visible; antennomere 3 short, slightly longer than wide, antennomere 41.6 times as long as antennomere 3, antennomeres 4-10 elongate, with short serrations; terminal antennomere simple, elongate, about 3 times as long as wide, about 1.3 times as long as antennomere 10, widest at two-thirds, apically narrowed and narrowly 


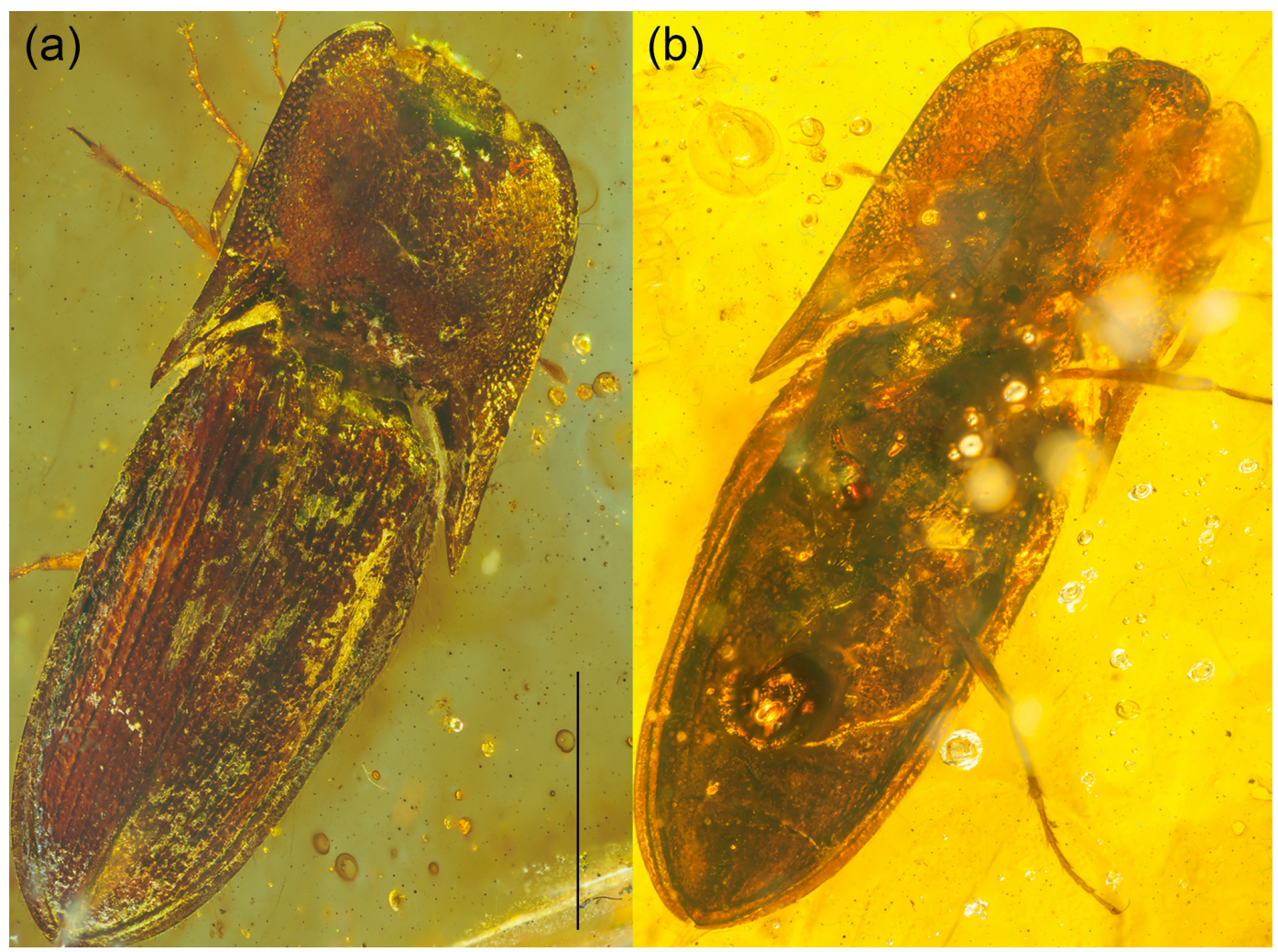

Figure 2. Cretopachyderes burmitinus gen. et sp. nov., holotype: (a) habitus, dorsal view; (b) habitus, ventral view. Scale bar equals 2.0 mm.

rounded. Mandible robust, relatively short, not well visible. Maxillary palpus moderately long; terminal palpomere securiform, apically flattened.

Pronotum (Figs. 1-3) weakly convex, without posterior angles widest at one-third, 1.45 times wider than long if measured along midline, and when posterior angles included then widest between their apices, and about 1.1 times longer than wide if length measured between anterior and posterior angles and width between the apices of posterior angles. Anterior margin widely concave; anterior angles very short; lateral sides rounded anteriorly, then sub-parallel; posterior angles very long, about 0.7 times as long as pronotal length when measured along midline, surpassing humeral part of elytra, gradually narrowed toward apex, relatively sharp, oriented posteriorly, with inner margin with distinct tooth and outer margin slightly concave; posterior margin medially emarginate. Lateral carina distinct, complete. Disc rather flattened, distinctly punctate; punctures sparser medially and denser and larger on sides, interstices smooth; sublateral carina distinct, coming from subapical inner part of posterior angle and running medially across whole length of posterior angle. Hypomeron somewhat shiny, with posterior margin subapically subrectangularly emarginate, with punctures distinct, large, separated 1.0-2.0 times of their diameter. Pronotosternal sutures almost straight, anteriorly open. Prosternum (Figs. 2b; 3c) elongate, about 2.7 times as long as wide including prosternal process, about 1.8 times as long as wide without prosternal process; prosternal lobe well developed, short, rounded; prosternal process robust, very slightly gradually narrowed toward apex, subapically abruptly narrowed. Scutellar shield (Figs. 1b; 2a; 3a; 4a) about 1.5 times as long as wide, narrowed subanteriorly, widest medially, then gradually narrowed toward apex, widely rounded anteriorly, narrowly rounded posteriorly, sides sinuate. Elytra (Figs. 1a, c; 2a, b; 3a, c; 4a, b) together about twice as long as wide (measured at widest place) and 2.5 times as long as pronotum; weakly convex, widest at basal third, then gradually slightly narrowed towards apex; each elytron basally distinctly but weakly emarginate, with striae formed by lines of fine punctures; interstriae smooth, slightly convex; pubescence sparse, semi-erect, moderately long, oriented apically; elytral epipleuron moderately narrowed behind metacoxae. Mesoventrite not well visible. Metaventrite rather short and wide, 1.25 times as wide as long, moderately convex, sparsely covered by punctures. Metacoxal plate (Fig. 2b) with basal portion well developed, wide, posteriorly widely roundly emarginate, then obliquely abruptly narrowed towards body edge. Hind wing not visible. Leg (Figs. 1a-c; 2a-b; 4d-h) slender, femur robust, elongate, ventrally with distinct groove for reception of tibia; tibia shorter than femur, densely covered with thick long sharp setae, without distinct spurs; tarsus slender, elongate, dis- 


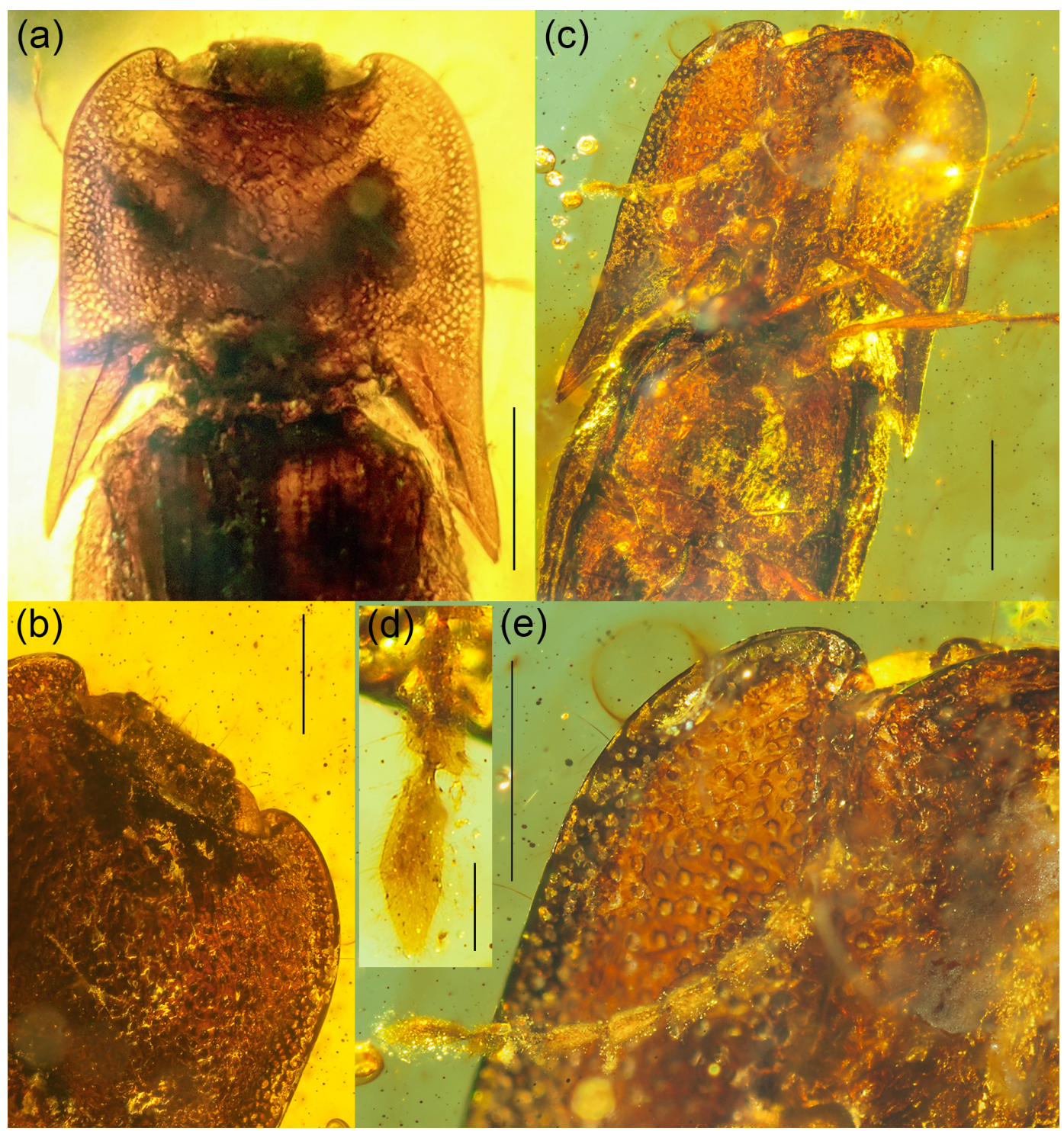

Figure 3. Cretopachyderes burmitinus gen. et sp. nov., holotype: (a) anterior part of body, dorsal view; (b) head and anterior part of pronotum, dorsal view; (c) anterior part of body, ventral view; (d) antennomeres 10 and 11; (e) antenna and anterior part of prothorax, ventral view. Scale bar equals $1.0 \mathrm{~mm}(\mathbf{a}, \mathbf{c}), 0.5 \mathrm{~mm}(\mathbf{b}, \mathbf{e})$, and $0.1 \mathrm{~mm}(\mathbf{d})$.

tinctly longer than tibia. Tarsomere I longest, slightly shorter than tarsomere II and III combined; length ratio of tarsomeres I-V 4.2:2.7 :2.0: $1.0: 3.0$; tarsomeres I-IV gradually shorter, simple, almost subparallel sided, only apically slightly widened, moderately densely covered by setae, which are denser and longer apically; apical tarsomere elongate, slender; claws (Fig. 4h) simple, slender, long, moderately curved.

Abdomen (Figs. 2b; 4c) with ventrites moderately densely covered by distinct punctures; ventrites 1-4 subequal in length; ventrite 5 about 1.35 times as long as ventrite 4 , subtriangular, narrowly rounded to subacute apically. Pregenital segments and genitalia not visible.

\section{Discussion}

Fossils play an important role not only in our understanding of the past diversity and evolutionary processes but also in the more accurate dating of phylogenetic events (Donoghue and Yang, 2016; Toussaint et al., 2017). Therefore, the reliable identification and systematic placement of the fossils are crucial tasks for taxonomists. The here described Cretopachyderes burmitinus gen. et sp. nov. belongs without any doubt to Elateridae based on its habitus, exposed labrum, projecting posterior angles of pronotum, concealed protrochantins, well-developed metacoxal plates, and presumably connate first four abdominal ventrites (Calder, 1996; Costa et al., 2010). Cretopachyderes gen. nov. is very distinctive due to 


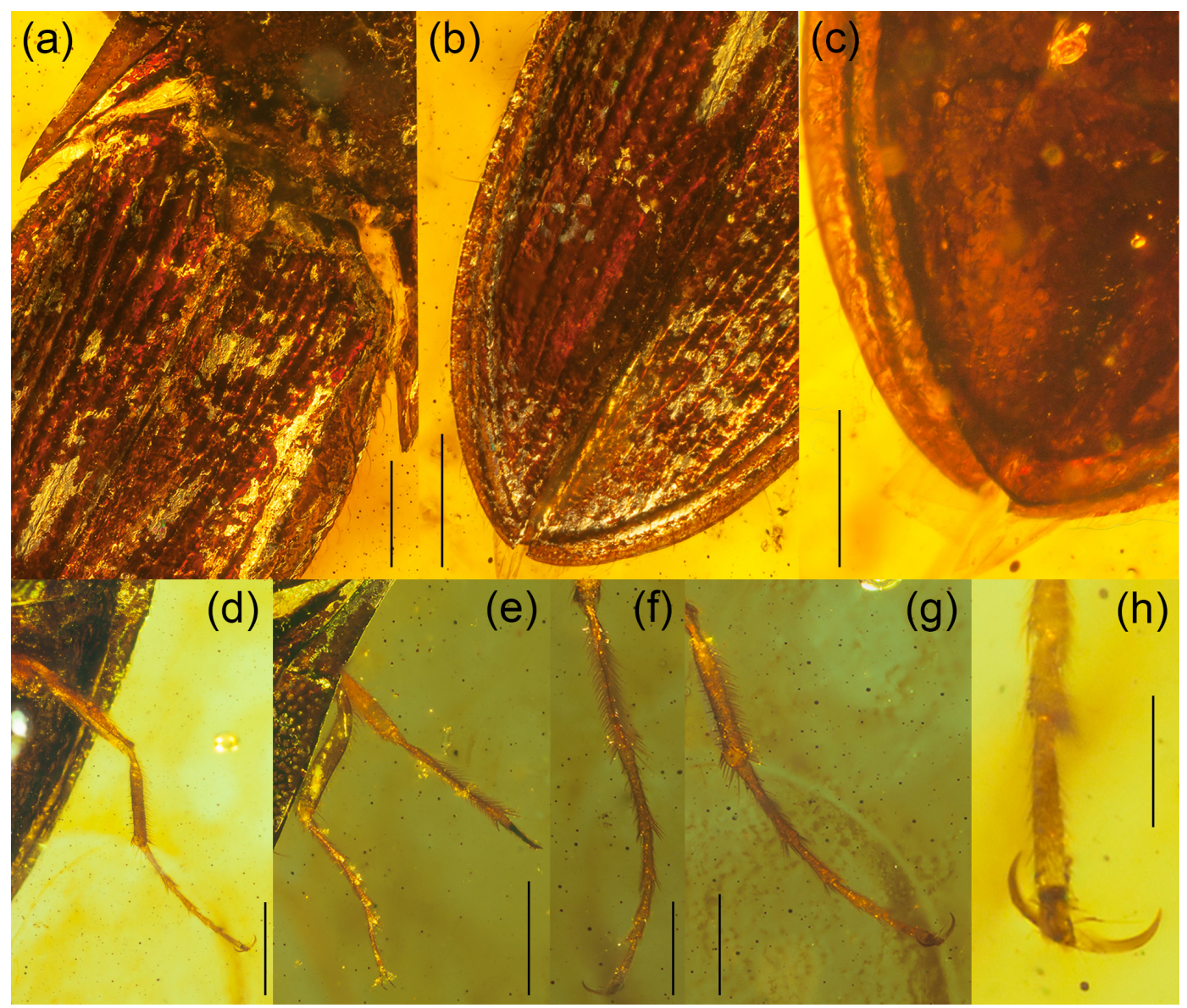

Figure 4. Cretopachyderes burmitinus gen. et sp. nov., holotype: (a) posterior part of pronotum, scutellar shield and anterior part of elytra, dorsal view; (b) apex of elytra, dorsal view; (c) apex of abdomen, ventral view; (d) metaleg, ventral view; (e) pro- and mesoleg, dorsal view; (f) metatibia and metatarsus, dorsal view; (g) metatibia and metatarsus, ventral view; (h) apical part of metatarsus with pretarsal claws, ventral view. Scale bar equals $0.5 \mathrm{~mm}(\mathbf{a}-\mathbf{e}), 0.3 \mathrm{~mm}(\mathbf{f}, \mathbf{g})$, and $0.1 \mathrm{~mm}(\mathbf{h})$.

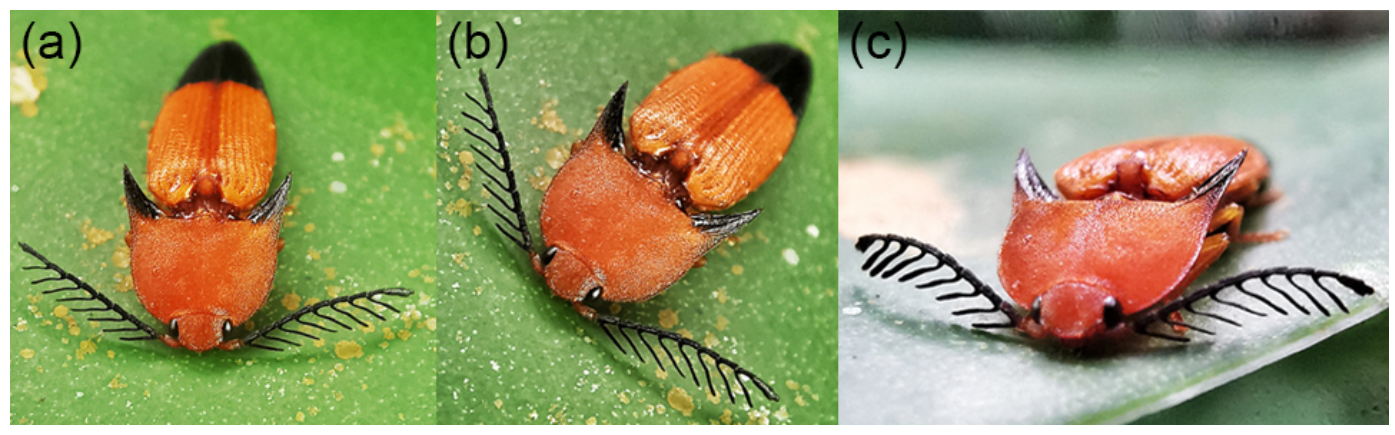

Figure 5. Live specimen of extant Pachyderes cf. apicalis Candèze, 1865, Singapore: (a, b) habitus, dorsal view; (c) detail of head, antennae and pronotum, fronto-dorsal view. Credit for photographs: Adeline Goh, Singapore.

its extremely elongate posterior angles of pronotum, which have never been reported in any fossil Elateridae. Additionally, this character is only rarely present in extant Elateridae, with the best examples being Dima spicata Schimmel, 1999 (Dendrometrinae: Dimini), and the representatives of genus Pachyderes Guérin-Méneville, 1829 (Fig. 5). Cretopachy- deres gen. nov. clearly differs from Dima spicata and other Dimini in having short antennae (vs. long, usually surpassing posterior angles of pronotum or even reaching half of elytra), the pronotal disc flattened (vs. distinctly convex; somewhat flattened in some Penia spp.), with sides more parallel-sided (vs. clearly rounded or sinuate) and with a short sublateral ca- 
rina which reach only the base of posterior angles (vs. long sublateral carina running along almost whole lateral carina), the head retracted to prothorax, the elytra more elongate (vs. oval to elongate-oval in most Dimini), the metacoxal plates well developed (vs. distinctly reduced towards elytra), and the tarsomeres simple (vs. at least some tarsomeres ventrally lobate) (Kundrata et al., 2018b; Qiu et al., 2020).

The new fossil genus is morphologically much more similar to Pachyderes - not only in the habitus and shape of pronotum with extremely pronounced posterior angles, but also in having the hypomeron with posterior margin subapically subrectangularly emarginate, body dorsally flattened, pronotosternal sutures almost straight, open anteriorly, head more or less depressed above, with straight anterior margin of frons, antennomeres III-X with elevated area at midline, absence of basal furrows on pronotum, prosternal lobe well developed, short and rounded, and prosternal process elongate, without subapical tooth. However, Pachyderes species have head not so retracted into prothorax (although this character in Cretopachyderes gen. nov. might be just an artifact caused by a defensive behavior possibly connected with the specimen preservation in amber), and especially they have tarsi about as long or only slightly longer than tibiae (vs. tarsi distinctly longer than tibiae), tarsomeres II-IV relatively much shorter and wider (vs. slender, distinctly elongate), and all of them or at least tarsomere IV apically distinctly widened and often ventrally lobate (vs. all tarsomeres simple). Pachyderes contains approximately 20 species known mainly from the South East Asia, with a few species reaching also India, Nepal, and China (e.g., Schenkling, 1925; Arimoto, 1993). This genus was placed either in a separate subfamily Pachyderinae (Fleutiaux, 1919; Schenkling, 1925), Conoderinae (current Oophorini) (Fleutiaux, 1928), tribe Pachyderini in Denticollinae (current Dendrometrinae) (Stibick, 1979), or tribe Oophorini in Agrypninae (Cate, 2007; Kundrata et al., 2019a). Most recent phylogenomic analysis of Elateridae (Douglas et al., 2021) showed that Pachyderes indeed belongs to Agrypninae but not to Oophorini and hence that the possible redefinition of Pachyderini and its resurrection from synonymy under Oophorini should be considered in future studies. Taking into consideration that based on the available evidence we consider Cretopachyderes gen. nov. related to Pachyderes and that Pachyderes was found outside Oophorini in recent phylogenetic analyses (Douglas et al., 2021), we tentatively place Cretopachyderes gen. nov. in Agrypninae incertae sedis until the classification of Pachyderes is firmly settled or until further, better preserved, material of Cretopachyderes gen. nov. shows that this genus should belong to another place in the Elateridae tree of life. One of the characters traditionally used for the definition of Agrypninae is a presence of setae basally on the pretarsal claws (Calder, 1996; Costa et al., 2010). There are no long setae on claws visible on the specimen of Cretopachyderes gen. nov.; however, they are often not well visible also on some recent Elateridae species (Robin Kundrata and Alexan- der S. Prosvirov, personal observation, 2021). Moreover, this character is not as stable as originally thought, since some Agrypninae obviously lack such setae and some members of other subfamilies possess them (Kundrata et al., 2018a).

The peculiar morphology of the newly discovered elaterid genus Cretopachyderes gen. nov. from the mid-Cretaceous Burmese amber significantly contributes to a better understanding of the palaeodiversity and evolution of the group. Further material of this interesting lineage may help us not only with its proper systematic placement but also with the recognition of the potential sexual dimorphism in this group. One would expect that the extremely pronounced posterior angles of pronotum are domain of the males only, but in extant Dima spicata and Pachyderes spp. there is no strong sexual dimorphism in this character (Qiu et al., 2020). Some species of Pachyderes have pectinate antennae, while females have serrate antennae, such as the examined specimen of Cretopachyderes gen. nov.; however, we do not know if the latter genus contained species with pectinate antennae.

Sample availability. The holotype of Cretopachyderes burmitinus gen. et sp. nov. is deposited in the collection of the Myanmar Amber Museum (MAM) (temporarily kept in the collection of Roger Long, USA).

Author contributions. RK conceived and designed the study. RK, ASP, RL, and GP carried out the morphological investigation. RL, $\mathrm{GP}$, and RK prepared figure plates. RK wrote the initial manuscript with help of ASP, RL, and GP. All authors discussed the results and edited, reviewed, and approved the manuscript.

Competing interests. The contact author has declared that neither they nor their co-authors have any competing interests.

Disclaimer. Publisher's note: Copernicus Publications remains neutral with regard to jurisdictional claims in published maps and institutional affiliations.

Acknowledgements. We are grateful to Alan Simpson (Ohio, USA) for help with the photographs and to Adeline Goh (Singapore) for her kind permission to use her photographs of live Pachyderes $\mathrm{cf}$. apicalis Candèze, 1865, from Singapore.

Financial support. This study was funded by the internal grant of the Faculty of Science, UP Olomouc (IGA_PrF_2021_019), to Robin Kundrata and Gabriela Packova and by the Russian Science Foundation (RSF) research project no. 21-74-10024, https: //rscf.ru/project/21-74-10024/ (last access: 30 October 2021; analysis of Pachyderes spp.), to Alexander S. Prosvirov. 
Review statement. This paper was edited by Carolin Haug and reviewed by Enrico Ruzzier and one anonymous referee.

\section{References}

Arimoto, H.: Some Pachyderes-species (Coleoptera, Elateridae) from Asia with the description of a new species, Gekkan-Mushi, 270, 9-13, 1993.

Bi, W.-X., He, J.-W., Chen, C.-C., Kundrata, R., and Li, X.-Y.: Sinopyrophorinae, a new subfamily of Elateridae (Coleoptera, Elateroidea), with the first record of a luminous click beetle in Asia and evidence for multiple origins of bioluminescence in Elateridae, ZooKeys, 864, 79-97, https://doi.org/10.3897/zookeys.864.26689, 2019.

Calder, A. A.: Click Beetles: Genera of the Australian Elateridae (Coleoptera), Monographs on invertebrate taxonomy, Vol. 2, CSIRO Publishing, Victoria, Australia, 401 pp., 1996.

Candèze, E. C. A.: Monographie des Élatérides, Tome premier, Mem. Soc. R. Sci. Liége, 12, 1-400, 1857.

Candèze, E. C. A.: Élatérides nouveaux, Mém. Acad. Belg., 17, 163, 1865.

Cate, P.: Elateridae, in: Catalogue of Palaearctic Coleoptera, edited by: Löbl, I. and Smetana, A., Volume 4, Apollo Books, Stenstrup, Denmark, 89-209, 2007.

Cockerell, T. D. A.: Insects in Burmese amber, Ann. Entomol. Soc. Am., 10, 323-329, 1917.

Costa, C., Lawrence, J. F., and Rosa, S. P.: Elateridae Leach, 1815, in: Handbook of Zoology, Arthropoda: Insecta; Coleoptera, Beetles, Volume 2: Morphology and Systematics (Elateroidea, Bostrichiformia, Cucujiformia partim), edited by: Leschen, R. A. B., Beutel, R. G., and Lawrence, J. F., Walter de Gruyter GmbH \& Co. KG, Berlin, Germany, 75-103, 2010.

Crowson, R. A.: The phylogeny of Coleoptera, Annu. Rev. Entomol., 5, 111-134, 1960.

Dolin, V. G.: K sistematike mezozoiskikh zhukov-schchelkunov (Coleoptera, Elateridae), Paleontol. Zhurnal., 9, 51-62, 1975.

Dolin, V. G.: Fossil click beetles (Coleoptera, Elateridae) of the subfamilies Negastriinae and Cardophorinae from Upper Jurassic of Karatau, Vestn. Zool., 1976, 68-75, 1976.

Dolin, V. G.: Click beetles (Coleoptera, Elateridae) from the Upper Jurassic of Karatau, in: Fossil Insects of the Mesozoic, edited by: Dolin, V. G., Panfilov, D. V., Ponomarenko, A. G., and Pritykina, D. N., Naukova Dumka, Kiev, Ukraine, 17-81, 1980.

Donoghue, P. C. J. and Yang, Z.: The evolution of methods for establishing evolutionary timescales, Philos. T. Roy. Soc. Lond. B, 371, 20160020, https://doi.org/10.1098/rstb.2016.0020, 2016.

Douglas, H. B., Kundrata, R., Brunke, A. J., Escalona, H. E., Chapados, J. T., Eyres, J., Richter, R., Savard, K., Ślipiński, A., McKenna, D., and Dettman, J. R.: Anchored Phylogenomics, Evolution and Systematics of Elateridae: Are All Bioluminescent Elateroidea Derived Click Beetles?, Biology, 10, 451, https://doi.org/10.3390/biology10060451, 2021.

Emery, C.: Ueber Phylogenie und Systematik der Insekten, Biol. Zentralbl., 5, 648-656, 1886.

Fleutiaux, E.: Insectes Coléoptères 13, Elateridae, Trixagidae et Melasidae. in: Voyage de Ch. Alluaud et R. Jeannel en Afrique Orientale (1911-1912), Résultats Scientifiques, Lhomme, Paris, $119,1919$.
Fleutiaux, E.: Les Élatérides de l'Indo-Chine Française (Catalogue raisonné), Deuxième Partie, Encyclopédie Entomologique, Coléoptères, 3, 120-121, 1928.

Guérin-Méneville, F. E.: Iconographie du règne animal de G. Cuvier, ou représentation d'aprés nature de l'une des espèces les plus remarquables, et souvent non encore figurées, de chaque genre d'animaux. Avec un texte descriptif mis au courant de la science. Ouvrage pouvant servir d'atlas a tous les traités de zoologie, Livraison 4, JB Baillière, Paris, pls. 11-12, 1829.

Kundrata, R. and Bocak, L.: Molecular phylogeny reveals the gradual evolutionary transition to soft-bodiedness in click-beetles and identifies Sub-Saharan Africa as a cradle of diversity for Drilini (Coleoptera: Elateridae), Zool. J. Linn. Soc., 187, 413452, https://doi.org/10.1093/zoolinnean/zlz033, 2019.

Kundrata, R., Gunter, N. L., Janosikova, D., and Bocak, L.: Molecular evidence for the subfamilial status of Tetralobinae (Coleoptera: Elateridae), with comments on parallel evolution of some phenotypic characters, Arthropod. Syst. Phylo., 76, 137145, 2018a.

Kundrata, R., Musalkova, M., and Kubaczkova, M.: Annotated catalogue of the click-beetle tribe Dimini (Coleoptera: Elateridae: Dendrometrinae), Zootaxa, 4412, 1-75, https://doi.org/10.11646/zootaxa.4412.1.1, 2018b.

Kundrata, R., Kubaczkova, M., Prosvirov, A. S., Douglas, H. B., Fojtikova, A., Costa, C., Bousquet, Y., Alonso-Zarazaga, M. A., and Bouchard, P.: World catalogue of the genusgroup names in Elateridae (Insecta, Coleoptera). Part I: Agrypninae, Campyloxeninae, Hemiopinae, Lissominae, Oestodinae, Parablacinae, Physodactylinae, Pityobiinae, Subprotelaterinae, Tetralobinae, ZooKeys, 839, 83-154, https://doi.org/10.3897/zookeys.839.33279, 2019a.

Kundrata, R., Prosvirov, A. S., Vondracek, D., and Sormova, E.: Congruence Between Molecular Data and Morphology: Phylogenetic Position of Senodoniini (Coleoptera: Elateridae), Insects, 10, 231, https://doi.org/10.3390/insects10080231, 2019b.

Kundrata, R., Packova, G., and Hoffmannova, J.: Fossil genera in Elateridae (Insecta, Coleoptera): A Triassic origin and Jurassic diversification, Insects, 11, 394, https://doi.org/10.3390/insects11060394, 2020.

Kundrata, R., Packova, G., Prosvirov, A. S., and Hoffmannova, J.: The Fossil Record of Elateridae (Coleoptera: Elateroidea): Described Species, Current Problems and Future Prospects, Insects, 12, 286, https://doi.org/10.3390/insects12040286, 2021.

Kusy, D., He, J.-W., Bybee, S. M., Motyka, M., Bi, W.-X., Podsiadlowski, L., Li, X.-Y., and Bocak, L.: Phylogenomic relationships of bioluminescent elateroids define the "lampyroid" clade with clicking Sinopyrophoridae as its earliest member, Syst. Entomol., 46, 111-123, https://doi.org/10.1111/syen.12451, 2021.

Leach, W. E.: Entomology, in: Edinburgh Encyclopaedia; Part I, edited by: Brewster, D., Volume 9, Blackwood, W., Waugh, J. etc., Edinburgh, UK, 57-172, 1815.

Linnaeus, C.: Systema Naturae per Regna Tria Naturae: Secundum Classes, Ordines, Genera, Species, Cum Characteribus, Differentiis, Synonymis, Locis, Tomus I, Editio Decima, Reformata, Laurentius Salvius, Stockholm, Sweden, 1-823, 1758.

Mao, Y., Liang, K., Su, Y., Li, J., Rao, X., Zhang, H., Xia, F., Fu, Y., Cai, C., and Huang, D.: Various amberground marine animals on Burmese amber with discussions on its age, Palaeoentomology, 
1, 91-103, https://doi.org/10.11646/palaeoentomology.1.1.11, 2018.

Muona, J., Chang, H., and Ren, D.: The clicking Elateroidea from Chinese Mesozoic deposits (Insecta, Coleoptera), Insects, 11, 875, https://doi.org/10.3390/insects11120875, 2020.

Otto, R. L.: Descriptions of two new elateroid beetles (Coleoptera: Eucnemidae, Elateridae) from Burmese amber, Insecta Mundi, 702, 1-6, https://doi.org/10.5281/zenodo.3673247, 2019.

Qiu, L., Németh, T., Prosvirov, A., and Kundrata, R.: Dima spicata Schimmel, 1999 (Elateridae: Dimini), a morphologically remarkable species endemic to China, Zootaxa, 4768, 415-424, https://doi.org/10.11646/zootaxa.4768.3.8, 2020.

Schenkling, S.: Elateridae I., in: Coleopterorum Catalogus, Pars 80, edited by: Schenkling, S., W. Junk, Berlin, Germany, 1-263, 1925.

Schimmel, R.: Neue und wenig bekannte Elateriden sowie eine neue Gattung, Acumenator n. gen., aus Südostasien (Insecta: Coleoptera, Elateridae), Mitt. Pollichia., 85 [1998], 231-259, 1999.
Shi, G., Grimaldi, D. A., Harlow, G. E., Wang, J., Wang, J., Yang, M., Lei, W., Li, Q., and Li, X.: Age constraint on Burmese amber based on U-Pb dating of zircons, Cret. Res., 37, 155-163, https://doi.org/10.1016/j.cretres.2012.03.014, 2012.

Stibick, J. N. L.: Classification of the Elateridae (Coleoptera), Relationships and classification of the subfamilies and tribes, Pacific Insects, 20, 145-186, 1979.

Toussaint, E. F. A., Seidel, M., Arriaga-Varela, E., Hájek, J., Král, D., Sekerka, L., and Fikáček, M.: The peril of dating beetles, Syst. Entomol., 42, 1-10, https://doi.org/10.1111/syen.12198, 2017.

Yu, T., Kelly, R., Mu, L., Ross, A., Kennedy, J., Broly, P., Xia, F., Zhang, H., Wang, B., and Dilcher, D.: An ammonite trapped in Burmese amber, P. Natl. Acad. Sci. USA, 116, 11345-11350, https://doi.org/10.1073/pnas.1821292116, 2019. 